\title{
Ritual Chiamsi dan Sinkaw Budaya Etnis Tionghoa Konghucu
}

\author{
Juandi Rusdianto, Suzy S. Azeharie \\ juandirusdiantoo@gmail.com,suzya@fikom.untar.ac.id \\ Fakultas Ilmu Komunikasi Universitas Tarumanagara
}

\begin{abstract}
The study entitled Chiamsi Ritual and Sinkaw Chinese Konghucu Ethnic Culture was conducted to find out how the ritual process occurred when the Confucian Chinese community performed Chiamsi and Sinkaw. This research uses descriptive qualitative research method because it is considered the most appropriate to answer the research problem formulation titled Chiamsi Ritual and Sinkaw Chinese Konghucu Ethnic Culture. The study will use interviews with four informants who were divided into two key informants, experts in Sinology and two informants who carried out the rituals of Chiamsi and Sinkaw. The research data obtained were sourced from interviews, observations and literature studies. The theory used in this research is the theory of ritual communication from Deddy Mulyana and Yermia Djefri Manafe and the transcendental theory from Deddy Mulyana and Engkus Kuswarno. This study found the forecast using Chiamsi and Sinkaw is a ritual process carried out by ritual implementers to find out the picture or handle life as a solution to the problems of his life. At each step of the ritual Chiamsi and Sinkaw transcendental communication occurs between the gods and humans.
\end{abstract}

Keywords: communication, Ritual, transcendental, Chiamsi and Sinkaw, Confucian

\begin{abstract}
Abstrak
Penelitian berjudul Ritual Chiamsi dan Sinkaw Budaya Etnis Tionghoa Konghucu dilakukan untuk mengetahui mengetahui bagaimana proses ritual yang terjadi saat masyarakat Tionghoa Konghucu melakukan Chiamsi dan Sinkaw. Penelitian ini menggunakan metode penelitian kualitatif deskriptif karena dianggap paling sesuai untuk menjawab rumusan masalah penelitian berjudul Ritual Chiamsi dan Sinkaw Budaya Etnis Tionghoa Konghucu. Penelitian akan menggunakan wawancara terhadap empat narasumber yang dibagi menjadi dua key informan ahli Sinologi dan dua informan pelaksana ritual Chiamsi dan Sinkaw. Data penelitian yang diperoleh bersumber dari wawancara, observasi dan studi pustaka. Teori yang digunakan dalam penelitian adalah teori komunikasi ritual dari Deddy Mulyana dan Yermia Djefri Manafe serta teori transendental dari Deddy Mulyana dan Engkus Kuswarno. Penelitian ini menemukan ramalan menggunakan Chiamsi dan Sinkaw merupakan proses ritual yang dilakukan pelaksana ritual untuk mengetahui gambaran atau pegangan hidup sebagai solusi atas masalah hidupnya. Pada setiap langkah ritual Chiamsi dan Sinkaw terjadi komunikasi transendental antara dewa dan manusia.
\end{abstract}

Kata Kunci : Ritual, Chiamsi, Sinkaw, Tionghoa, Konghucu

\section{Pendahuluan}

Etnis Tionghoa masuk ke Indonesia berabad-abad yang lalu. Menurut Gayatri, et al., etnis Tionghoa mulai masuk ke Hindia Belanda pada abad ke-15 (Gayatri et al., 2019). 
Layaknya Indonesia,etnis Tionghoa juga menganut berbagai agama seperti Buddha, Katolik, dan Kristen secara resmi dan di antaranya ada juga yang mengaku menganut agama Konghucu (Tanggok, 2017).

Etnis Tionghoa yang masuk ke Indonesia tidak serta merta meninggalkan tradisi dan kebudayaan mereka. Menurut Gayatri et al. dari sumber yang sama, etnis Tionghoa pendatang ini disebut juga sebagai "Cina Totok" atau "singkhe" yang berarti tamu baru. Sebutan "totok" ini muncul karena para pendatang Tionghoa ini tetap melakukan kebiasaan dan kebudayaan asli walaupun sudah di tempat tinggal baru, yaitu Indonesia (Gayatri et al., 2019).

Kebiasaan dan kebudayaan asli Cina Totok ini tentunya bukan hanya satu atau dua saja. Menurut M. Ikhsan Tanggok, kebiasaan dan kebudayaan asli ini sangat beragam, mulai dari istilah keluarga dan kekerabatan, kosmologi, agama, pemujaan leluhur, praktik magi, dan lain sebagainya (Tanggok, 2017).

Norma yang diteruskan secara turun-temurun mengalir seiring dengan perkembangan zaman. Kebiasaan, praktik dan tradisi terus hidup dan berkembang serta diwariskan pada generasi berikutnya (Azeharie, et al., 2019).

Salah satu kebiasaan dan kebudayaan asli yang dibawa oleh etnis Tionghoa sampai saat ini adalh Chiamsi dan Sinkaw. Menurtut M. Ikhsan Tanggok, Chiamsi adalah batang bambu yang biasa digunakan untuk melihat keberuntungan atau ramalan. Sinkaw sendiri merupakan kayu atau tembaga yang bentuknya menyerupai pinang dibelah dua, fungsinya untuk membenarkan ramalan Chiamsi (Tanggok, 2017).

Ritual dilakukan karena memiliki tujuan yang ingin dicapai. Masih dari sumber yang sama, ritual Chiamsi dan Sinkaw adalah kegiatan yang dilakukan untuk berkomunikasi dengan para dewa yang bertujuan untuk meminta petunjuk dan ramalan akan jodoh, kesehatan, dan rezeki (Tanggok, 2017).

Ada tata cara untuk melakukan ritual Chiamsi dan Sinkaw. Menurut Eric Walter Rothenbuhler dalam Yeremia Djefri Manafe, ritual adalah kebiasaan atau rutinitas yang bertujuan untuk memberikan pengaruh dalam kehidupan (Manafe, 2011).

Ketika etnis Tionghoa ingin mendapatkan ramalan atau petunjuk untuk kehidupan mereka, mereka berkomunikasi kepada para dewa melalui Chiamsi dan Sinkaw. Edmund Husserl dalam Engkus Kuswarno mengatakan bahwa dalam komunikasi transendental terdapat perbedaan antara fakta dan esensi sehingga perlu menggabungkan dari apa yang terjadi dan apa yang menjadi gambaran dari pelaksana ritual (Kuswarno, 2009).

Peneliti tertarik untuk meneliti tentang ritual Chiamsi dan Sinkaw karena ingin mengetahui ritual yang dilakukan masyarakat Tionghoa Konghucu saat melakukan Chiamsi dan Sinkaw. Alasan lain adalah karena belum pernah ditemukan penelitian bertema seperti ini.

\section{Metode Penelitian}

Menurut Juliansyah Noor, penelitian deskriptif merupakan penelitian yang berusaha mendeskripsikan suatu gejala, peristiwa, kejadian yang sedang terjadi sekarang. Penelitian deskriptif memusatkan perhatian pada masalah aktual sebagaimana adanya pada saat penelitian berlangsung. Melalui penelitian deskriptif, peneliti berusaha mendeskripsikan peristiwa dan kejadian yang menjadi pusat 
perhatian tanpa memberikan perlakuan khusus terhadap peristiwa tersebut (Noor, 2017).

Sejalan dengan Juliansyah Noor, Chaedar Alwasilah berpendapat bahwa penelitian kualitatif deskriptif untuk menampilkan deksripsi kental atau thick description. Deskripsi juga harus menyajikan interpretasi, bukan sekedar fakta-fakta yang teramati sehingga data yang dikumpulkan haruslah tepat dan lengkap (Alwasilah, 2017).

Sebagaimana yang dijelaskan Juliansyah Noor dan Chaedar Alwasilah, M. Hariwijaya berpendapat bahwa penelitian deskriptif ditujukan untuk mengumpulkan informasi aktual secara rinci yang melukiskan kejadian yang ada. Penelitian deskriptif juga mengidentifikasi masalah atau memeriksa kondisi dan praktekpraktek yang berlaku (Hariwijaya, 2015).

Berdasarkan teori di atas, peneliti merangkum bahwa metode penelitian deskriptif adalah metode yang digunakan untuk mendeskripsikan gejala, peristiwa, atau kejadian yang terjadi pada saat penelitian dilakukan tanpa memberikan perlakuan khusus pada kejadian tersebut. Metode deskriptif digunakan dalam penelitian ini karena dianggap paling sesuai untuk menjawab rumusan masalah penelitian berjudul Ritual Chiamsi dan Sinkaw Budaya Etnis Tionghoa Konghucu.

\section{Hasil Temuan dan Diskusi}

\section{Chiamsi dan Sinkaw}

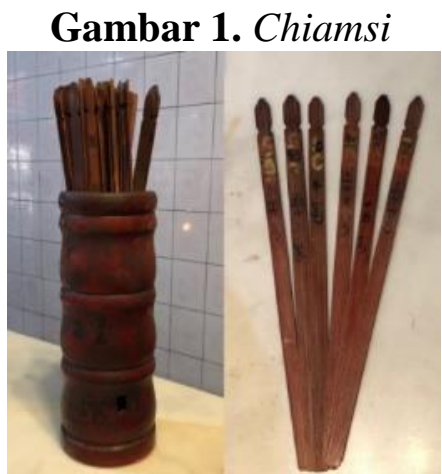

Sumber: Dokumentasi Pribadi diambil pada 8 Desember 2019

Dalam hasil wawancara dengan narasumber Toto, Chiamsi merupakan potongan-potongan papan bambu kecil yang disimpan dalam tabung di klenteng. Di setiap papan bambunya terdapat nomor sebagai acuan untuk mendapatkan jawaban pertanyaan yang diajukan. Ada beberapa langkah untuk menggunakan Chiamsi. Pertama, pelaksana ritual harus mengacak papan-papan bambu yang ada di dalam tabung. Kedua, pelaksana ritual memutar tabung Chiamsibeserta isinya di atas tempat dupa yang biasa disebut hiolo searah jarum jam sebanyak tiga putaran. Ketiga, pelaksana ritual akan mengocok tabung Chiamsi tabung yang diarahkan ke depan sampai menjatuhkan satu papan bambu. Jika yang keluar lebih dari satu papan bambu maka pelaksana ritual akan merapihkan papan-papan bambu yang berserakan lalu mengulang kembali dari langkah pertama. Angka di bambu Chiamsi yang keluar tidak langsung menjadi jawaban atas pertanyaan pelaksana ritual. Pelaksana ritual perlu memastikannya menggunakan Sinkaw kemudian mengambil jawaban di kertas sesuai nomor yang benar. Kertas dapat diambil di rak yang sudah disediakan sesuai 
dengan nomornya (wawancara dengan Toto di Vihara Hok Teng Tjeng Sin, Kebayoran Lama pada tanggal 15 Desember 2019 pukul 08.56 WIB).

Gambar 2. Rak yang berisi kertas hasil ramalan Chiamsi

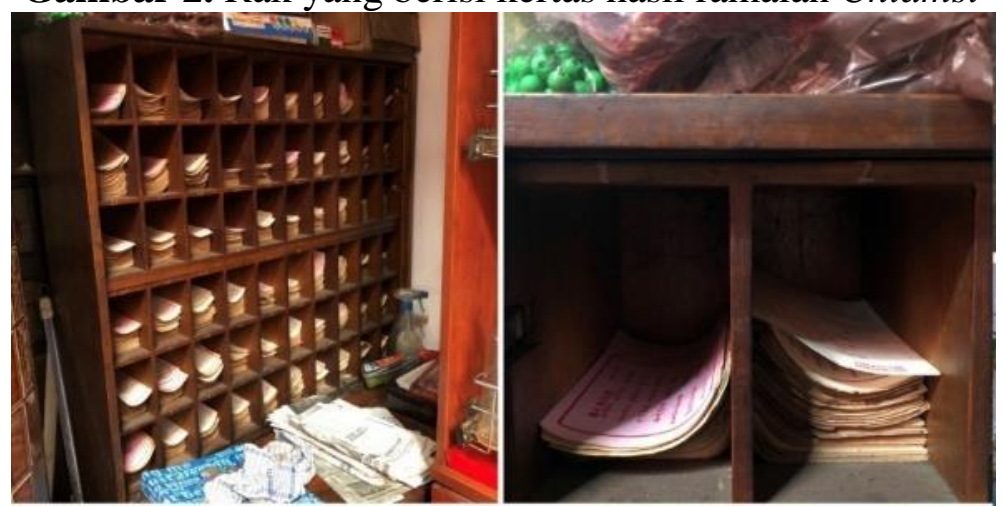

Sumber: Dokumentasi Pribadi pada 8 Desember 2019

Gambar 3. Kertas Jawaban Chiamsi

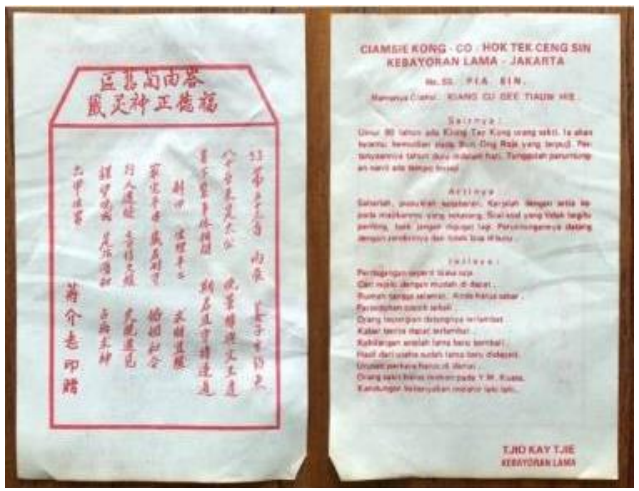

Sumber: Dokumentasi Pribadi pada 8 Desember 2019

Kertas jawaban Chiamsi biasanya berisi syair Cina klasik, bukan merupakan jawaban yang spesifik. Untuk mengetahui jawaban yang spesifik seperti tahun kapan seseorang harus berhati-hati, tahun yang akan mujur, pantangan, jodoh, dan lain-lain harus ditanyakan kepada ahli Kuamia. Chiamsi tidak akan bermakna bila syair Cina klasik ini tidak dibawakan ke ahli Kuamia untuk dibacakan bersama dengan $\mathrm{BaZi}$ atau delapan aksara pelaksana ritual (wawancara dengan Eddy Prabowo Witanto di rumahnya, Tanjung Duren pada tanggal 7 Desember 2019 pukul 19.10 WIB).

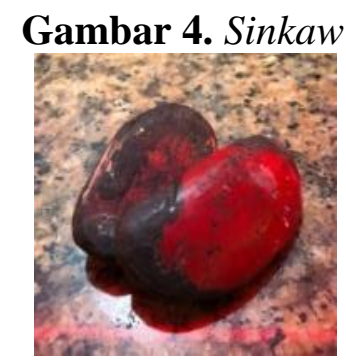

Sumber: Dokumentasi Pribadi pada 8 Desember 2019

Sinkaw adalah kayu satu tangkap yang digunakan untuk berkomunikasi dengan dewa. Penggunaan Sinkaw ini tidak hanya menggunakan kayu satu tangkap tapi juga bisa menggunakan dua koin yang sama, sepasang tempurung kura-kura atau 
apapun yang berbentuk serupa (wawancara dengan Eddy Prabowo Witanto di rumahnya, Tanjung Duren pada tanggal 7 Desember 2019 pukul 19.10 WIB).

Untuk menggunakan Sinkaw, pelaksana ritual perlu sembahyang terlebih dahulu menggunakan dupa di klenteng. Setelah sembahyang, pelaksana ritual akan mengambil Sinkaw, memutarnya di atas hiolo searah jarum jam sebanyak tiga kali dan meminta izin kepada dewa untuk bertanya tentang permasalahan hidup kemudian Sinkaw dilempar bebas (wawancara dengan Eddy Prabowo Witanto di rumahnya, Tanjung Duren pada tanggal 7 Desember 2019 pukul 19.10 WIB).

Toto juga menambahkan bahwa dari Sinkaw terdapat tiga tanda yaitu disetujui, ditertawakan dan ditegur. Jawaban disetujui adalah ketika posisi Sinkaw terlentang dan tertelungkup. Jawaban ditertawakan adalah bila kedua Sinkaw berposisi terlentang. Jawaban ditegur adalah bila posisi Sinkaw tertelungkup keduaduanya. Jawaban ditegur berarti pelaksana ritual sudah mengetahui jawabannya tapi masih ditanyakan pada dewa (wawancara dengan Toto di Vihara Hok Teng Tjeng Sin, Kebayoran Lama pada tanggal 15 Desember 2019 pukul 08.56 WIB).

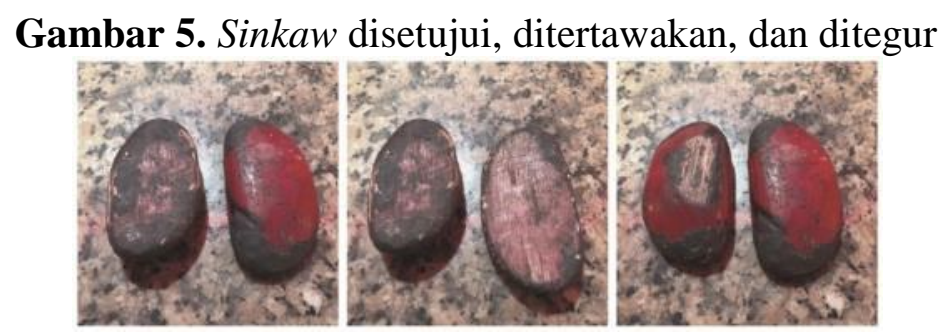

Sumber: Dokumentasi Pribadi pada 8 Desember 2019

Hasil ini sesuai dengan kepercayaan etnis Tionghoa tentang keseimbangan atau yin danyang. Jika seimbang berarti setuju dan jika tidak seimbang berarti tidak setuju. Oleh karena itu bila kedua Sinkaw tertelungkup atau terlentang artinya tidak disetujui. Sebaliknya, bila Sinkaw tertelungkup dan terlentang maka artinya disetujui (wawancara dengan Chai Kun Lim di ruko Cianjur, Jembatan Besi pada tanggal 9 Desember 2019 pukul 10.57 WIB).

\section{Sejarah Chiamsi dan Sinkaw}

Meramal melalui Chiamsi dan Sinkaw sudah ada sejak zaman nenek moyang. Pada zamannya, etnis Tionghoa meramal dengan menggunakan berbagai media, seperti retakan tempurung kura-kura, yang digunakan untuk menanyakan musim tanam, musim panen dan lain sebagainya. Setelah aksara mandarin atau HanZi (汉字) muncul, cara berkomunikasi pun semakin berkembang sampai akhirnya munculah Chiamsi dan Sinkaw sebagai media komunikasi kepada dewa (wawancara dengan Eddy Prabowo Witanto di rumahnya, Tanjung Duren pada tanggal 7 Desember 2019 pukul 19.10 WIB).

Ritual Chiamsi dan Sinkaw tetap ada sampai saat ini karena diwariskan entah secara langsung maupun tidak langsung. Ada yang karena melihat praktik, penasaran dan mempelajarinya, ada juga yang karena diajarkan secara langsung oleh orang tuanya masing-masing. Praktik meramal lewat Chiamsi dan Sinkaw saat ini masih berjalan walaupun banyak juga etnis Tionghoa generasi muda yang tidak percaya dan tidak melakukannya lagi (wawancara dengan Toto di Vihara Hok Teng Tjeng Sin, Kebayoran Lama pada tanggal 15 Desember 2019 pukul 08.56 WIB). 
Sebagai salah satu kebudayaan Tionghoa, Chiamsi dan Sinkaw merupakan aliran Taoisme. Cara meramal menggunakan Chiamsi dan Sinkaw tidak akan punah karena manusia mempercayai adanya kekuatan di luar logika manusia. Ketika mengalami masalah, manusia akan mencari cara untuk berkomunikasi dengan kekuatan di luar logika manusia ini atau yang biasa disebut Tuhan. Ketika orang merasa belum mendapatkan jawaban atas doanya, maka manusia akan mencari cara untuk mendapatkan jawaban dari doanya, salah satunya adalah dengan meramal melalui Chiamsi dan Sinkaw (wawancara dengan Eddy Prabowo Witanto di rumahnya, Tanjung Duren pada tanggal 7 Desember 2019 pukul 19.10 WIB).

Ritual Sinkaw juga tidak akan lepas dari kebudayaan Tionghoa karena pada etnis Tionghoa diajarkan untuk menghormati leluhurnya sesuai dengan filsafat Konghucu. Sehingga akan ada saat etnis Tionghoa yang masih memegang kebudayaan asli akan melakukan sembahyang kubur atau Ceng Beng, cara komunikasi yang digunakan kepada leluhur adalah dengan menggunakan Sinkaw. Hal inilah yang membuat Chiamsi dan Sinkaw tetap digunakan sampai saat ini (wawancara dengan Toto di Vihara Hok Teng Tjeng Sin, Kebayoran Lama pada tanggal 15 Desember 2019 pukul 08.56 WIB).

\section{Proses Ritual Chiamsi dan Sinkaw}

Sebelum melakukan ritual Chiamsi dan Sinkaw pelaksana ritual diharuskan memiliki kebersihan jiwa dan raga. Kebersihan jiwa dengan tidak memikirkan hal yang buruk dan percaya terhadap jawaban yang akan diberikan nanti. Kebersihan raga dilakukan dengan mencuci tangan atau mandi sebelum melakukan sembahyang di klenteng menggunakan dupa (wawancara dengan Toto di Vihara Hok Teng Tjeng Sin, Kebayoran Lama pada tanggal 15 Desember 2019 pukul 08.56 WIB).

Setelah membersihkan diri pelaksana ritual melakukan sembahyang dengan dupa lalu mengambil Sinkaw yang diputar di atas dupa yang sama. Sinkaw digunakan untuk meminta izin apakah diperbolehkan bertanya melalui Chiamsi (wawancara dengan Eddy Prabowo Witanto di rumahnya, Tanjung Duren pada tanggal 7 Desember 2019 pukul 19.10 WIB).

Gambar 6. Peneliti memutar Sinkaw di atas hiolo dan meminta izin kepada dewa

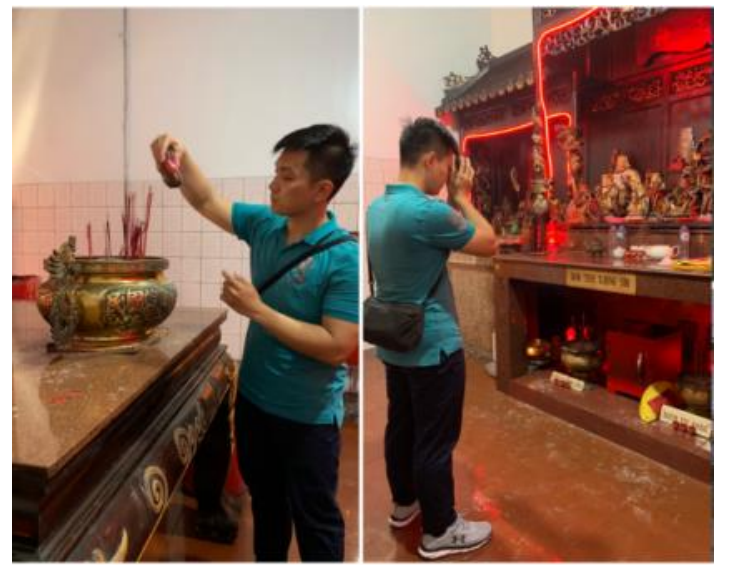

Sumber: Dokumentasi Pribadi pada 8 Desember 2019 
Gambar 7. Peneliti melempar Sinkaw

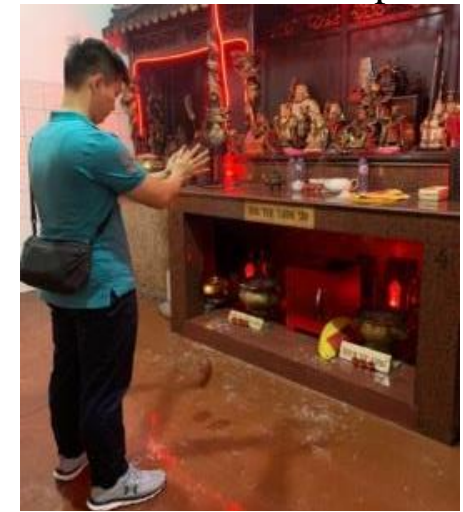

Sumber: Dokumentasi Pribadi pada 8 Desember 2019

Jika diperbolehkan, maka pelaksana ritual boleh langsung melanjutkan ritual. Namun bila tidak diperbolehkan tiga kali berturut-turut maka pelaksana ritual harus membersihkan diri dengan mencuci wajah dan tangan kembali. Jika sudah mencuci tangan dan wajah namun masih tidak diperbolehkan, maka lebih baik tidak perlu dipaksakan untuk bertanya melalui Chiamsi(wawancara dengan Toto di Vihara Hok Teng Tjeng Sin, Kebayoran Lama pada tanggal 15 Desember 2019 pukul 08.56 WIB).

Eddy juga menambahkan bila pelaksana ritual tetap memaksakan untuk bertanya maka akan berdampak buruk bagi pelaksana ritual. Karena personifikasi manusia terhadap dewa, dewa dipercaya dapat marah bila dibantah. Lain halnya jika disetujuimaka pelaksana ritual dapat langsung melanjutkan ritual dengan mengambil Chiamsi dan mengacak papan-papan bambunya kemudian Chiamsi diputar searah jarum jam sebanyak tiga putaran di atas dupa yang sama. Hal ini bertujuan agar Chiamsi "berisi" dan menghasilkan jawaban yang tepat. Setelah diputar, Chiamsi dikocok sambil diarahkan ke depan agar mengeluarkan satu batang papan bambu. Bila lebih dari satu papan bambu yang keluar, maka itu dianggap tidak sah dan papan-papan bambu yang berserakan harus dirapihkan ke dalam tabung serta mengulang ritualdari awal yaitu memutar Chiamsi di atas dupa (wawancara dengan Eddy Prabowo Witanto di rumahnya, Tanjung Duren pada tanggal 7 Desember 2019 pukul 19.10 WIB).

Gambar 8. Peneliti mengocok Chiamsi

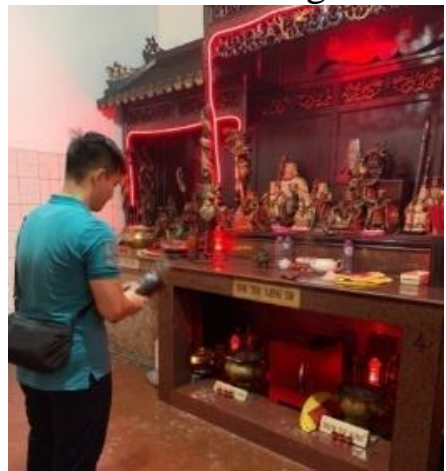

Sumber: Dokumentasi Pribadi pada 8 Desember 2019 
Bila keluar satu papan bambu saja, nomor di bambu akan dilihat dan ditancapkan di hiolo atau tempat dupa. Setelah itu, pelaksana ritual mengambil Sinkaw dan memutar di atas dupa searah jarum jam sebanyak tiga putaran. Dengan Sinkaw, pelaksana ritual bertanya kepada dewa apakah nomor sekian merupakan jawaban yang tepat atas pertanyaan yang diajukan, kemudian Sinkaw dilempar (wawancara dengan Toto di Vihara Hok Teng Tjeng Sin, Kebayoran Lama pada tanggal 15 Desember 2019 pukul 08.56 WIB).

Gambar 9. Nomor di papan bambu Chiamsi

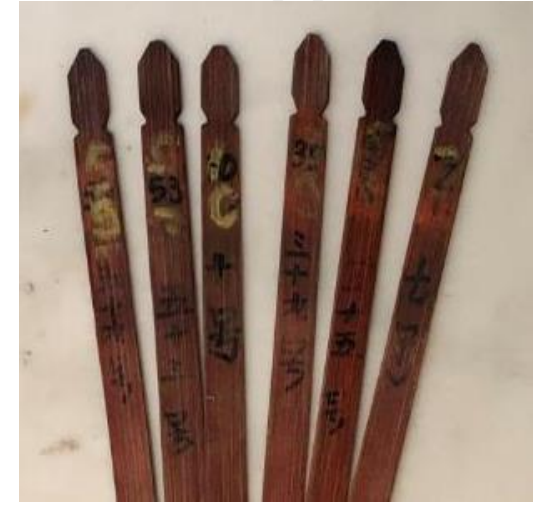

Sumber: Dokumentasi Pribadi pada 8 Desember 2019

Gambar 10. Peneliti menancapkan papan bambu Chiamsi di hiolo

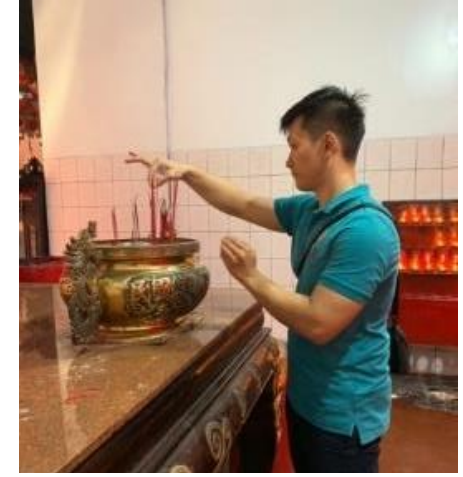

Sumber: Dokumentasi Pribadi pada 8 Desember 2019

Jika tidak disetujui, maka papan Chiamsi yang telah ditancapkan di hiolo harus dibersihkan dari abu dupanya dan dimasukkan kembali ke dalam tabung Chiamsi. Kemudian ritual diulang kembali dari mengacak papan-papan bambu Chiamsi dan diputar di atas dupa. Jika disetujui berarti jawaban dari Chiamsi sudah tepat. Pelaksana ritual akan berterima kasih pada dewa dan merapihkan kembali Chiamsi dan Sinkaw yang telah dipakai (wawancara dengan Toto di Vihara Hok Teng Tjeng Sin, Kebayoran Lama pada tanggal 15 Desember 2019 pukul 08.56 WIB).

Setelah mengucapkan terima kasih dan merapihkan Chiamsi dan Sinkaw, pelaksana ritual akan mengambil hasil ramalan sesuai dengan nomor yang tertulis di papan bambu. Jawaban dari Chiamsi tertera di atas kertas sesuai nomornya. Jawabannya berupa syair Cina klasik dengan perlambang yang tidak akan langsung dipahami bila dibaca secara sendiri. Di beberapa klenteng ada yang sudah menerjemahkan syair Cina klasik tersebut, namun jawabannya bersifat umum dan kurang spesifik. Jika pelaksana ritual ingin menanyakan hal-hal spesifik seperti 
tahun baik, tahun yang harus berhati-hati, tahun yang akan mujur, pantangan, jodoh, dan lain-lain maka pelaksana ritual harus meminta seorang ahli melihat nasib atau yang biasa disebut Kuamia untuk membacakan arti yang sebenarnya berdasarkan $B a Z i$ atau delapan aksara pelaksana ritual yang berisi tahun lahir, bulan lahir, tanggal lahir, dan jam lahir pelaksana ritual berdasarkan penanggalan imlek. Untuk meramal menggunakan Chiamsi dan Sinkaw tidak perlu membayar tapi jika pelaksana ritual ingin berdana uang tentunya sangat diperbolehkan (wawancara dengan Eddy Prabowo Witanto di rumahnya, Tanjung Duren pada tanggal 7 Desember 2019 pukul 19.10 WIB).

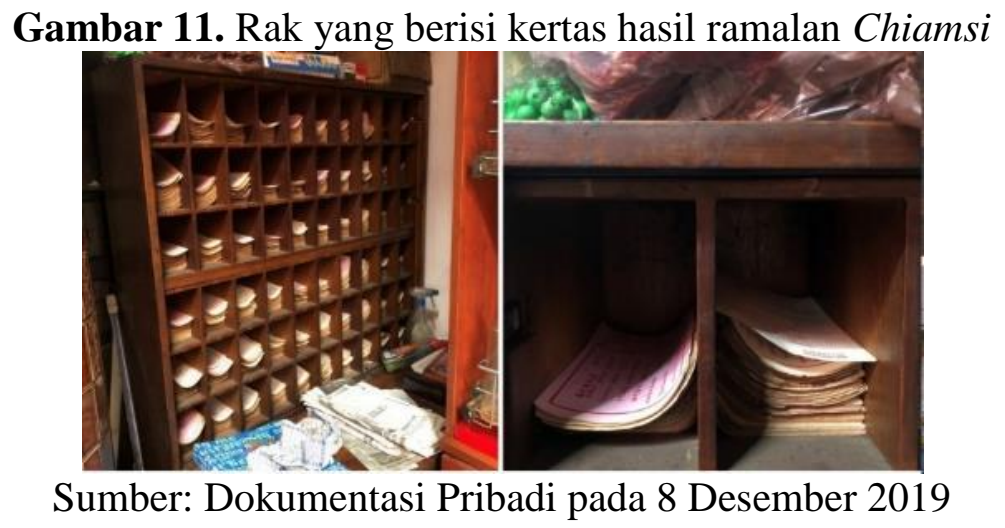

\section{Pandangan Etnis Tionghoa Terhadap Chiamsi dan Sinkaw}

Etnis Tionghoa memandang Chiamsi dan Sinkaw sebagai media untuk berkomunikasi dengan dewa untuk menanyakan kepastian atau solusi atas hal yang dipertanyakan. Pertanyaan biasanya bersifat individual dan hanya ditanyakan ketika etnis Tionghoa merasa menghadapi jalan buntu dalam permasalahan hidupnya (wawancara dengan Eddy Prabowo Witanto di rumahnya, Tanjung Duren pada tanggal 7 Desember 2019 pukul 19.10 WIB).

Sejalan dengan Eddy Prabowo Witanto, Toto berpendapat bahwa etnis Tionghoa selain menanyakan masalah yang tidak bisa diselesaikan, juga dapat menanyakan ketika mereka sedang mengalami keraguan dengan menggunakan Chiamsi danSinkaw. Walaupun banyak yang mempercayai dan menggunakan Chiamsi danSinkaw, ada juga etnis Tionghoa yang tidak melakukannya (wawancara dengan Toto di Vihara Hok Teng Tjeng Sin, Kebayoran Lama pada tanggal 15 Desember 2019 pukul 08.56 WIB).

Chai Kun Lim berpendapat bahwa etnis Tionghoa generasi lama atau berusia lanjut masih mempercayai Chiamsi dan Sinkaw sebagai media untuk menanyakan solusi atas masalah yang sedang dihadapi. Berbeda dengan generasi lama, saat ini cukup banyak etnis Tionghoa generasi muda yang cenderung tidak mempercayai Chiamsi dan Sinkaw sebagai media untuk mencari solusi atas masalah yang mereka hadapi karena dianggap kuno (wawancara dengan Chai Kun Lim di ruko Cianjur, Jembatan Besi pada tanggal 9 Desember 2019 pukul 10.57 WIB).

Kepercayaan generasi muda etnis Tionghoa terhadap Chiamsi dan Sinkaw tergantung pada individual dari masing-masing orang. Ketika generasi muda mengalami masalah terberat dalam hidup yang membuat dirinya merasa putus asa, mereka akan melakukan segala cara untuk mendapatkan solusi atas masalah yang dihadapi termasuk melakukan ChiamsidanSinkaw. Bila mereka melakukan ChiamsiSinkaw di saat seperti ini, mereka akan mendapatkan jawaban yang akan 
menjadi pegangan atau gambaran atas apa yang akan dihadapi kedepannya dan itu akan membuat mereka percaya terhadap Chiamsi danSinkaw (wawancara dengan Toto di Vihara Hok Teng Tjeng Sin, Kebayoran Lama pada tanggal 15 Desember 2019 pukul 08.56 WIB).

Eddy Prabowo Witanto meneruskan bahwa etnis Tionghoa yang tidak percaya tentunya akan meninggalkan Chiamsi dan Sinkaw. Namun ini tidak akan membuat Chiamsi dan Sinkaw punah karena etnis Tionghoa yang percaya akan tetap melakukan Chiamsi dan Sinkaw dan mendapatkan hasil yang sesuai untuk masalah hidup mereka. Kepercayaan ini akan menular dengan sendirinya sehingga ritual Chiamsi dan Sinkaw tidak akan punah (wawancara dengan Eddy Prabowo Witanto di rumahnya, Tanjung Duren pada tanggal 7 Desember 2019 pukul 19.10 WIB).

Hal ini sejalan dengan apa yang dibahas oleh Dance tentang pengertian psikologis komunikasi. Psikologis komunikasi menurut Dance meneliti kesadaran dan pengalaman dari manusia. Berdasarkan hal itu, Fisher membagi ciri pendekatan psikologis dalam komunikasi menjadi empat yaitu: (1) penerimaan stimuli secara indrawi, (2) proses yang mengantarai stimuli dan respon, (3) prediksi respon, dan (4) peneguhan respon (Supratman \& Mahadian, 2016: 29).

Berdasarkan teori di atas dapat disimpulkan bahwa ketika etnis Tionghoa mengalami masalah kehidupan, mereka memiliki nalar untuk memilih respon atas masalah tersebut. Menurut pandangan mereka terhadap orang lain yang pernah melakukan Chiamsi dan Sinkaw di saat mengalami masalah kehidupan dapat menemukan solusi yang sesuai permasalahannya sehingga etnis Tionghoa akan mencoba untuk meramal menggunakan Chiamsi dan Sinkaw. Setelah melakukan dan mendapatkan solusi yang tepat atas permasalahan mereka, etnis Tionghoa akan mempercayai ramalan Chiamsi dan Sinkaw sebagai media yang tepat untuk meramal kehidupan sehingga ritual Chiamsi dan Sinkaw tidak akan punah.

\section{Simpulan}

Ramalan menggunakan Chiamsi dan Sinkaw adalah proses ritual ketika pelaksana ritual berkomunikasi dengan dewa untuk menanyakan tentang ramalan hidup yang nantinya akan menjadi gambaran atau pegangan hidup dan menyelesaikan masalah pelaksana ritual. Pada setiap langkah ritual Chiamsi dan Sinkaw terjadi komunikasi transendental antara dewa dan manusia. Pada saat sembahyang terjadi komunikasi satu arah dari manusia ke dewa. Pada saat menggunakan Chiamsi, Sinkaw, dan menerjemahkan makna syair Cina klasik terjadi komunikasi dua arah antara dewa dan manusia karena ada tanda yang terjadi. Proses ritual Chiamsi dan Sinkaw harus diawali dengan jiwa dan raga yang bersih. Setelah itu, pelaksana ritual akan memulai ramalan dari sembahyang, meminta izin menggunakan Sinkaw, mengocok tabung Chiamsi untuk mendapatkan jawaban, mempertanyakan kebenaran jawaban dengan Sinkaw, dan menerjemahkan makna syair Cina klasik kepada ahli melihat nasib atau yang biasa disebut Kuamia. Untuk pelaksana ritual yang menjalankan hidupnya berdasarkan hasil ramalannya akan membuat hidup pelaksana ritual lebih tenang dan nyaman karena mengetahui langkah apa yang perlu dilakukan dalam hidupnya. Lain halnya ketika pelaksana ritual tidak melakukan apa yang dianjurkan ramalan, pelaksana ritual akan mengalami hal-hal yang tidak baik dalam hidupnya karena telah dianggap tidak mematuhi dewa. Semua orang yang ingin melakukan Chiamsi dan Sinkaw boleh melakukan ritual tersebut, hanya perempuan yang sedang menstruasi saja yang tidak 
diperbolehkan karena dipercaya raga perempuan yang sedang menstruasi dianggap kotor.

\section{Ucapan Terima Kasih}

Peneliti mengucapkan terimakasih kepada kedua orangtua, adik-adik dan pasangan peneliti, key informan dan informan yang telah bersedia meluangkan waktunya serta semua pihak yang telah memberikan dukungan dan bantuan kepada peneliti selama proses penyusunan jurnal penelitian ini.

\section{Daftar Pustaka}

Afrizal. (2017). Metode Penelitian Kualitatif: sebuah upaya mendukung penggunaan penelitian kualitatif dalam berbagai disiplin ilmu / Prof. Dr. Afrizal, M.A. Depok: Rajawali Pers.

Agustinova, Danu Eko (2015). Memahami Metode Penelitian Kualitatif Teori dan Praktik. Yogtakarta: CALPULIS.

Alwasilah, A Chaedar. (2017). Pokoknya Kualitatif. Pustaka Jaya: Bandung.

Ariokunto, Suharsimi. (2005). Manajemen Penelitian. Jakarta: Rineka Cipta.

Azeharie, Suzy., Paramita, Sinta., Sari, Wulan Purnama. (2019). Studi Budaya Non Material Warga Jaton. Jurnal ASPIKOM, 3, 1153-1162.

Fauzan, Almanshur., \& Djunaidi, Ghony. (2012). Metodologi Penelitian Kualitatif. Jogjakarta: Ar-Ruzz Media.

Hariwijaya. (2015). Metodologi dan Penulisan Skripsi, Tesis dan Disertasi untuk Ilmu Sosial dan Humanoria. Parama Ilmu.

Indrawati, Rachmi. (2018). Metode Penelitian Kualitatif: manajemen dan bisnis konvergensi teknologi informasi dan komunikasi / Indrawati, Ph.D.;editor penerbit, Rachmi. Bandung: Refika Aditama.

Koentjaraningrat. (1983). Metode-metode Penelitian Masyarakat. Gramedia.

Manafe, Yermia Djefri (2011). Komunikasi Ritual pada Budaya Bertani Atoni Pah Meto di Timor-Nusantara Tenggara Timur. Jurnal Komunikasi, 1, 289.

Manziliati, Asfi. (2017). Metodologi Penelitian Kualitatif: Paradigma, Metode, dan Aplikasi. Jakarta: Universitas Brawijaya Press (UB Press).

Nazir. (2011). Metode Penelitian. Jakarta: Ghalia Indonesia.

Noor, Juliansyah. (2017). Metodologi Penelitian: Skripsi, Tesis, Disertasi, dan Karya Ilmiah. Jakarta: Kencana.

Sudaryono. (2018). Metode Penelitian. Depok: Rajawali Pers.

Sugiyono. (2010). Metode Penelitian Pendidikan Pendekatan Kuantitatif, kualitatif dan $R \& D$. Bandung: Alfabeta.

Tehubijuluw, Florentina., Sugiarto.(2014). Metode Penelitian: cara mudah membuat makalah, skripsi, tesis, dan disertasi/ Dr.Florentina K. Tehubijuluw, S. Sos, MBM, Prof. Dr. Ir. Sugiarto, M. Sc.; editor, Dr. Florentina K. Tehubijuluw S. Sos, MBM. Tangerang: PT. Matana Bina Utama.

Tanggok, Ikhsan, (2017), Agama dan Kebudayaan Orang Hakka di Singkawang. Jakarta: PT Kompas Media Nusantara. 